\title{
Sequential synthesis of free-standing high quality bilayer graphene from recycled nickel foil
}

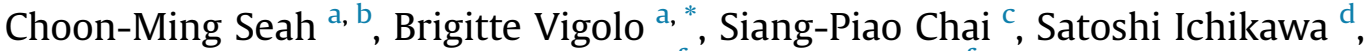 \\ Jérôme Gleize ${ }^{\mathrm{e}}$, François Le Normand ${ }^{\mathrm{f}}$, Fitsum Aweke ${ }^{\mathrm{f}}$, Abdul Rahman Mohamed ${ }^{\mathrm{b}}$ \\ a Institute Jean Lamour, CNRS-Université de Lorraine, BP 70239, 54506, Vandœuvre-lès-Nancy, France \\ b School of Chemical Engineering, Engineering Campus, Universiti Sains Malaysia, 14300, Nibong Tebal, Seberang Perai Selatan, P. Pinang, Malaysia \\ c Chemical Engineering Discipline, School of Engineering, Monash University, Jalan Lagoon Selatan, 46150, Bandar Sunway, Selangor, Malaysia \\ d Institute for NanoScience Design, Osaka University, 1-3, Machikaneyama-cho, Toyonaka, Osaka, 560-8531, Japan \\ e Laboratoire de Chimie Physique, Approche Multi-échelle de Milieux Complexes, Université de Lorraine, 1 Bd Arago, 57078, Metz, France \\ ${ }_{\mathrm{f}}^{\mathrm{f}}$ ICube - Laboratoire des sciences de l'ingénieur, de l'informatique et de l'imagerie (ICube), Equipe MaCEPV, Université de Strasbourg, CNRS, Bat 28, 23 rue \\ du Loess, 67037, Strasbourg Cedex, France
}

\section{A R T I C L E I N F O}

Article history:

Received 28 May 2015

Received in revised form

14 September 2015

Accepted 19 September 2015

Available online 21 September 2015

\begin{abstract}
A B S T R A C T
The recycle and reuse of catalyst is an active research area motivated by the reduction of graphene production cost. Our process is derived from the conventional CVD method widely utilized for graphene synthesis. It allows the formation of uniform bilayer graphene by limiting the segregation of carbon. The relatively thick foil of $\mathrm{Ni}$ used as catalyst plays a crucial role in solubilizing and trapping large amount of carbon adatoms. The trapping mechanism is enhanced by the high-speed cooling subsequent to the growth stage. Segregation of carbon is then efficiently quenched and uniform bilayer graphene could be prepared. The separation process is also optimized thanks to a protective effect from the nickel carbide $\left(\mathrm{Ni}_{3} \mathrm{C}\right)$ formed. We show that $\mathrm{Ni}_{3} \mathrm{C}$ minimizes the catalyst lost due to the separation of graphene and it also facilitates the graphene separation process. The Ni foil could be recycled up to 6 times without significant variation in number of layers and perfectness in crystallinity of the obtained bilayer graphene. Besides, we discuss of the role playing by the roughness of the catalyst surface for bilayer graphene separation in our process.
\end{abstract}

(c) 2015 Elsevier Ltd. All rights reserved.

\section{Introduction}

Graphene is made up of a single or few layers of $\mathrm{sp}^{2}$-bonded carbon atoms arranged in a two-dimensional honeycomb structure [1]. Graphene is an attractive material due to its remarkable electronic properties. The recent advances in the synthesis of large-area graphene have opened up a post-silicon era. Among many methods ever reported, Chemical Vapor Deposition (CVD) and sublimation of $\mathrm{SiC}$ are currently the most favorable approaches for obtaining graphene in wafer-scale. CVD has attracted much more attentions than other methods attributing to its simpler synthesis process and easier in its subsequent separation of graphene from the substrate [2]. The transfer of graphene from its original substrate to the arbitrary substrate without deteriorating graphene crystallinity is a

\footnotetext{
* Corresponding author.

E-mail address: Brigitte.Vigolo@univ-lorraine.fr (B. Vigolo).
}

challenging task. To date, the majority of researchers are still either using the wet-chemical etching or the mechanical exfoliation for separation of graphene from its substrate. Mechanical exfoliation would impose severe mechanical defects onto the basal plane of graphene. On the other hand, wet-chemical etching is more preferable as the process would cause fewer defects to the graphene sheets. However, the catalyst (substrate) will be consumed during the course of separation and it is impractical particularly when single crystal catalyst is used to grow graphene. Therefore, reuse and recycle of catalyst is necessary; but, due to the difficulty in the controlled etching of catalyst foil, the reports on the reuse of catalyst for synthesizing wafer-scale graphene are rarely found. Sophisticated approach, that utilizing electrolysis cell to delaminate the graphene from $\mathrm{Cu}$ and $\mathrm{Pt}$ foils was demonstrated recently [3,4]. Three cycles of repeated growth and separation of graphene over $\mathrm{Cu}$ foils were successfully carried out [3]. When Pt foils were used, the authors could repeatedly grow graphene on the same Pt foil over 100 times [4]. To preserve the graphene crystallinity, oxidative 
decoupling transfer which is an improved delamination process was also demonstrated [5]. However, all the aforementioned approaches are relatively complicated and involved multiple process steps.

$\mathrm{Cu}$ and $\mathrm{Ni}$ are the two common catalysts used for the growth of graphene through CVD. The formation of monolayer graphene is easier to be achieved with $\mathrm{Cu}$ as the $\mathrm{Cu}$ possesses lower carbon solubility. On the other hand, Ni has relatively higher carbon solubility as compared to that of $\mathrm{Cu}$ and the solubility of carbon into the bulk $\mathrm{Ni}$ at $900{ }^{\circ} \mathrm{C}$ is ca. 0.9 at\% [6,7], meanwhile almost no carbon can "dissolve" into Cu [8]. During the cooling process after the growth of graphene, the carbon would segregate out from the $\mathrm{Ni}$ catalyst to form mainly multilayer graphene. Moreover, the bonding between $\mathrm{Ni}$ and graphene was calculated to be the mix of chemisorption and physisorption with high adhesion energy [9], making it hard to separate graphene using mechanical approach. On the other hand, the graphene formation mechanism over $\mathrm{Ni}$ catalyst is highly debatable. It was proposed that $\mathrm{Ni}_{2} \mathrm{C}$ is formed in the CVD, which led to the formation of graphene on the surface of $\mathrm{Ni}$ [10-12]. However, this theory is not agreed by some researchers [13-15]. Meanwhile, the presence of other form of metastable carbide with the formula of $\mathrm{Ni}_{3} \mathrm{C}$ is generally unnoticed. In this paper, we demonstrate for the first time to our knowledge a simple method to enable the recycle of $\mathrm{Ni}$ foils for repeated growth of wafer scale bilayer graphene, which is more difficult to grow as compared with monolayer graphene through applying rapid cooling after the CVD. We show that $\mathrm{Ni}_{3} \mathrm{C}$ formed under a very rapid cooling stage plays the role as a protection layer for the Ni foils from excessive etching by etchants.

\section{Experiment section}

Nickel (Ni) foil (99.9\% purity, Sigma-Aldrich) with a thickness of ca. $125 \mu \mathrm{m}$ and polycrystalline surface was cut into $10 \mathrm{~mm} \times 10 \mathrm{~mm}$ and used as the catalyst to grow bilayer graphene. The graphene was synthesized by CVD and the detailed set-up was reported earlier $[16,17]$. The detail of the furnace setup and the strategy to enable the very rapid cooling is shown in supporting information (Fig. S1). Generally, the Ni foil was placed in a quartz boat and then located at the center of the furnace. The Ni foil was then heated from room temperature up to $900{ }^{\circ} \mathrm{C}$ with a heating rate of $10^{\circ} \mathrm{C} / \mathrm{min}$. During the heating, high purity $\mathrm{H}_{2}$ gas (99.999\%) with a flowrate of $80 \mathrm{sccm}$ was flowed into the quartz tube to reduce the oxide present on the Ni surface. As the desired temperature was obtained, high purity $\mathrm{CH}_{4}(99.999 \%)$ was fed into the reactor at a flowrate of $20 \mathrm{sccm}$, the $\mathrm{H}_{2}$ flowrate remaining the same. After 5 min of reaction, the quartz boat along with the Ni foil was displaced from the heating zone to ambient temperature zone for rapid cooling. The temperature of the $\mathrm{Ni}$ foil was cooled to $50{ }^{\circ} \mathrm{C}$ in roughly $10-15$ of seconds; the average cooling rate for the $\mathrm{Ni}$ to room temperature $\left(30{ }^{\circ} \mathrm{C}\right)$ was estimated to be higher than $900{ }^{\circ} \mathrm{C} \mathrm{min}{ }^{-1}$. At the same time, $\mathrm{CH}_{4}$ and $\mathrm{H}_{2}$ gases were switched off and $\mathrm{N}_{2}$ gas (99.999\%) subsequently introduced into the quartz tube to quench the reaction.

Once the temperature cooled to room temperature, the graphene/Ni was taken out from the reactor for graphene separation process. 2 different etchants namely aqueous iron (III) nitrate and nitric acid with different concentrations, by diluting nitric acid (65\%, Merck) and iron(III) nitrate nonahydrate (>99.95\%, Sigma-Aldrich) were used. 4 edges of graphene/Ni foil were scrubbed with sand paper ( 800 mesh) to provide the opening for direct contact between $\mathrm{Ni}$ and the etchant. It was then floated on nitric acid and aqueous iron nitrate solution. After the graphene and $\mathrm{Ni}$ were separated, the iron nitrate and nitric acid were diluted with huge amount of DI water to minimize the contamination on the graphene sheet. It was then transferred onto silicon/silicon oxide $(1000 \AA)$ wafer for characterization. Meanwhile, the remaining $\mathrm{Ni}$ foil can be easily removed from iron nitrate solution or nitric acid and rinsed with DI water. The surface of Ni was polished with sand paper to obtain a smooth surface and later placed into the reactor for the subsequent reaction. These steps were repeated until the $\mathrm{Ni}$ foil was too thin to be handled by hands or holes were observed.

High Resolution Transmission Electron Microscope (HRTEM) image of the graphene samples were taken by Tecnai 20 at $200 \mathrm{keV}$ (Fei company). A Reinashaw inVia Raman Microscope with laser excitation of $633 \mathrm{~nm}$ was used for the point-based Raman spectroscopy. Meanwhile the Raman mapping was carried out by a Horiba LabRAM HR 800 micro-Raman spectrometer with the same laser. Atomic Force Microscopy (AFM) analysis was performed using a Park System XE-100. Meanwhile for the X-ray Diffraction (XRD) analysis, it was completed with INEL CPS120 with cobalt Kalpha X-ray for a scan range $2 \theta$ of $0-110^{\circ}$. XPS analysis was achieved in a conventional VSW apparatus equipped with a monochromatic $\mathrm{Al}$ source and a $150 \mathrm{~mm}$ hemispherical electron detector. The binding energies were calibrated with $\mathrm{Ni} 2 \mathrm{p} 3 / 2$ line at $852.3 \mathrm{eV}$. Core level spectra are recorded with an experimental resolution of $0.65 \mathrm{eV} \mathrm{Ni}_{3} \mathrm{C}$ compound in low amount in the samples was unstable under the X-ray beam. Therefore its detection without evolution was only possible at low incident power (240 Watts) for the sample before separation.

\section{Results}

A facile approach was proposed to transfer bilayer graphene from $\mathrm{Ni}$ foil. Firstly, the graphene/Ni substrate after CVD was scrubbed with sand paper at its 4 edges. The purpose is to expose $\mathrm{Ni}$ to the etchant during the separation stage. To prevent unnecessary contamination, we avoided coating of protective layer on the bilayer graphene. The sample was directly "floated" on the surface of the etchant solution (nitric acid). The nitric acid etched and intercalated between $\mathrm{Ni}$ foil and bilayer graphene started from the edge to the center (Fig. 1(a)). Graphene is highly hydrophobic, and thus it will not submerge into the nitric acid. On the other hand, the $\mathrm{Ni}$ foil with high density tends to sink. The sinking of the Ni foil in the solution provided a gentle force in tearing the graphene from the Ni foil. Eventually the bilayer graphene and $\mathrm{Ni}$ foil was totally separated (Fig. 1(b)), but the edges of bilayer graphene were slightly deteriorate. The concentration of nitric acid plays a very important role to preserve the $\mathrm{Ni}$ foil and also the graphene as well. A vigorous process would etch away quite large amount of surface layer of the $\mathrm{Ni}$ foil. If high concentration of acid is applied, it will etch away the whole Ni foil rapidly. At the same time, the hydrogen bubbles formed during the vigorous oxidation of $\mathrm{Ni}$ foil could subsequently break the bilayer graphene on top into small pieces. If the concentration of acid is too low, the separation process becomes very slow. The whole Ni foil especially at the edges exposed to acid at longer period would suffer damage and be unable to be reused as catalyst. From our study, nitric acid with concentration of $1.44 \mathrm{~mol} /$ L (6.5\%) was a good compromise to preserve the Ni substrate. However, we could reuse the Ni foil only twice; after that, the Ni foil was too thin to be able to be handled by hand. The thickness of remaining nickel foil after the first separation was of $75 \mu \mathrm{m}$ and after the polishing process only $52 \mu \mathrm{m}$ left. The nickel foil was completely etched away during the second cycle. Furthermore, the overall uniformity of the grown bilayer graphene at the second cycle was not comparable with that obtained at the first cycle.

Considering that the etching capability of iron nitrate solution is relatively weaker compared with nitric acid, we further explore the possibility of recycling of $\mathrm{Ni}$ foil if iron nitrate solution was applied for bilayer graphene separation. Fig. 2(a) shows the process of 

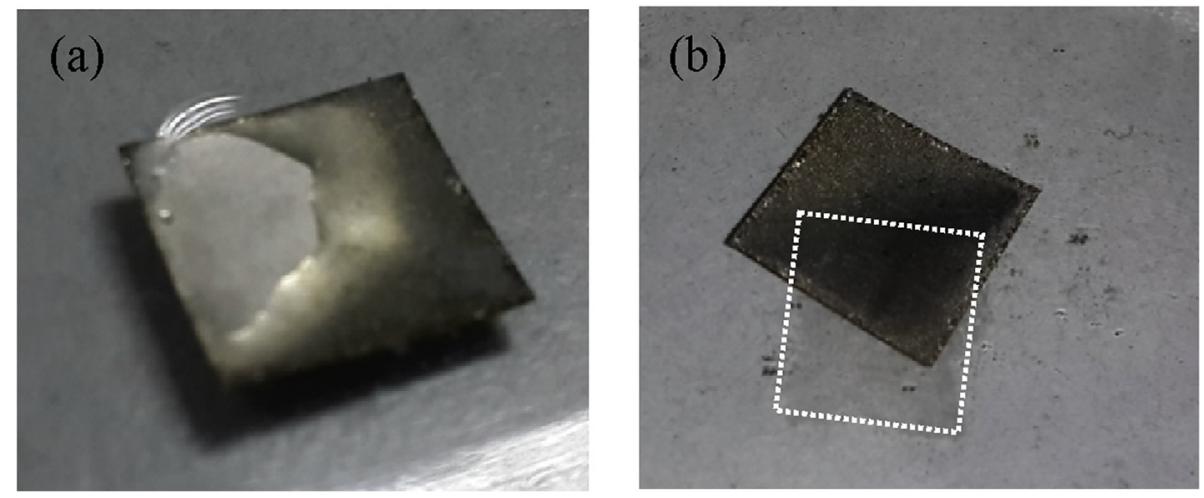

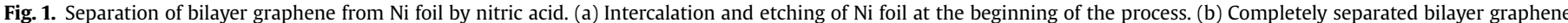
from Ni foil that is submerged into nitric acid. The separated graphene is in the white box. (A colour version of this figure can be viewed online.)
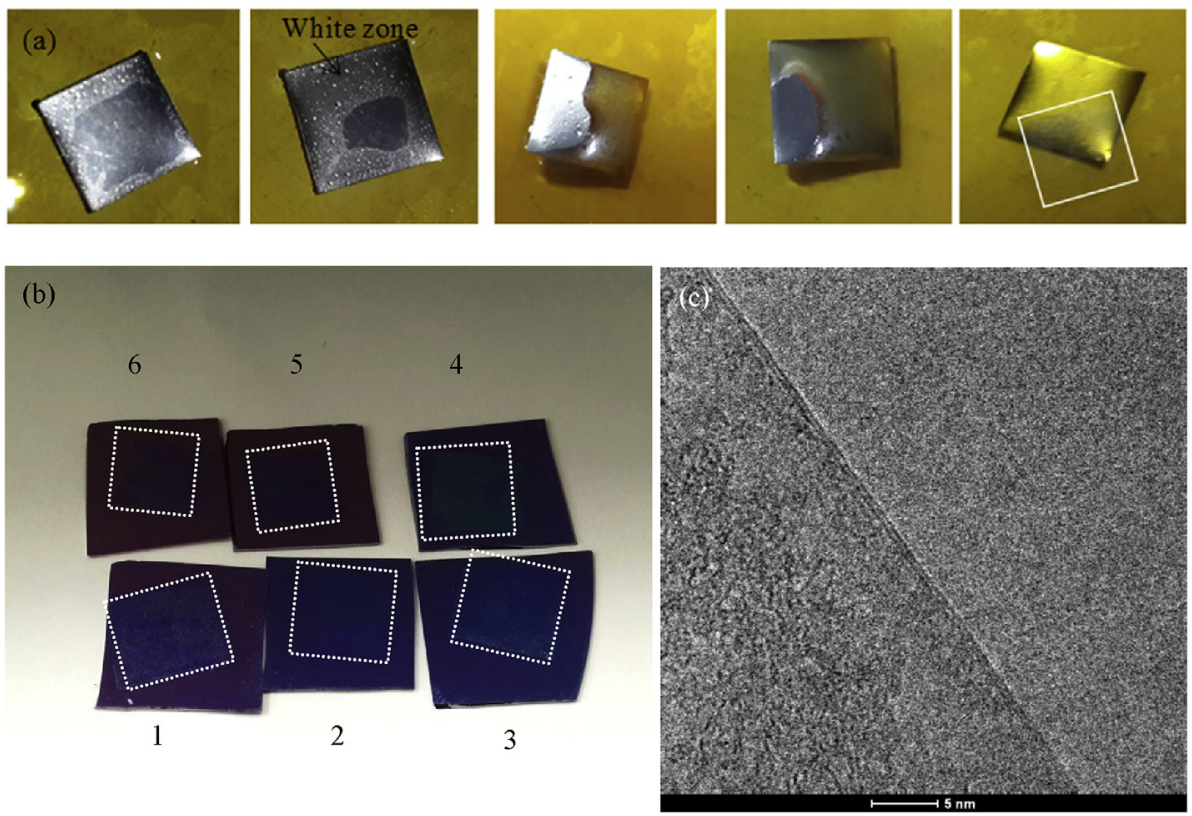

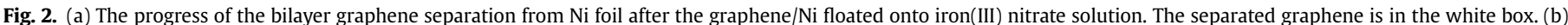

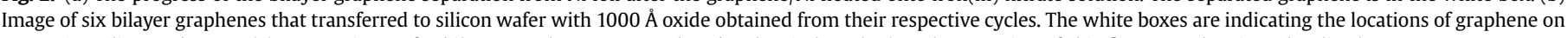
respective silicon substrate. (c) HRTEM image for bilayer graphene separated under the sixth cycle. (A colour version of this figure can be viewed online.)

graphene separation from $\mathrm{Ni}$ foil under the interaction of iron nitrate. The observed behavior was different than that shown for the separation through nitric acid (Fig. 1). From Fig. 2(a), a "white zone" started to appear at the edge of the foil between bilayer graphene and $\mathrm{Ni}$; it resulted from the intercalation and partial etching by iron nitrate solution. The strong interaction between bilayer graphene and Ni was obviously broken and the "white zone" was enlarged with time and eventually it covered all the Ni foil. Meanwhile, the weight of $\mathrm{Ni}$ applied a gentle force to tear the graphene from $\mathrm{Ni}$ foil during it sinking. The same phenomenon was observed regardless of how many cycles the Ni foil was used for CVD and the subsequent bilayer graphene separation. From our current study, we managed to recycle the $\mathrm{Ni}$ foil up to 6 times and the graphene samples were shown in Fig. 2(b). Under characterization of HRTEM, we found that the graphene synthesized under sixth 6th cycles was mostly bilayers (Fig. 2(c)). Meanwhile, HRTEM images were taken at other random spots in the sample, and all giving 2 parallel straight lines characteristic, which is typical observation for bilayer graphene (Fig. S2 $(\mathrm{a}-\mathrm{c})$ ). Meanwhile, regarding the use of iron nitrate, the concentration of $0.50 \mathrm{~mol} / \mathrm{L}$ was the most efficient for the separation. Further increase of the concentration of iron nitrate solution did not give any significant enhancement for the process and a lower concentration $(0.25 \mathrm{~mol} / \mathrm{L})$ did not favor the intercalation mechanism even after several days.

From Raman spectroscopy analysis, three primary peaks at $c a$. $1350 \mathrm{~cm}^{-1}$, ca. $1600 \mathrm{~cm}^{-1}$ and ca. $2680 \mathrm{~cm}^{-1}$ indicates D-band, Gband and 2D-band respectively. Fig. 3(a) containing all 6 Raman spectra of graphene under 6 cycles of separation, it is clear that the peaks for D-band are very weak as compared to G-band, indicating the high crystallinity perfectness of the graphene [18]. For all 6 spectra, the ratio of $\mathrm{I}_{2 \mathrm{D}} / \mathrm{I}_{\mathrm{G}}$ is in the range of $0.979-1.352$, meanwhile the full width half maximum (fwhm) in the range of $40-50 \mathrm{~cm}^{-1}$, within the range for bilayer graphene [19-21]. To further verify the uniformity of the graphene, Raman mapping was carried out at the graphene grown under the sixth cycle (Fig. 3(b) and (c)). The fwhm in the range of $43-46 \mathrm{~cm}^{-1}$, while the ratio of $\mathrm{I}_{2 \mathrm{D}} / \mathrm{I}_{\mathrm{G}}$ is in the range of 1.03-1.35, suggesting the present of uniform bilayer graphene, in agreement with the observation obtained by HRTEM (Fig. 2(c)), irrespective to the number of time that the catalyst has been recycled. Sheet resistance of the bilayer graphene was also tested 
(a)
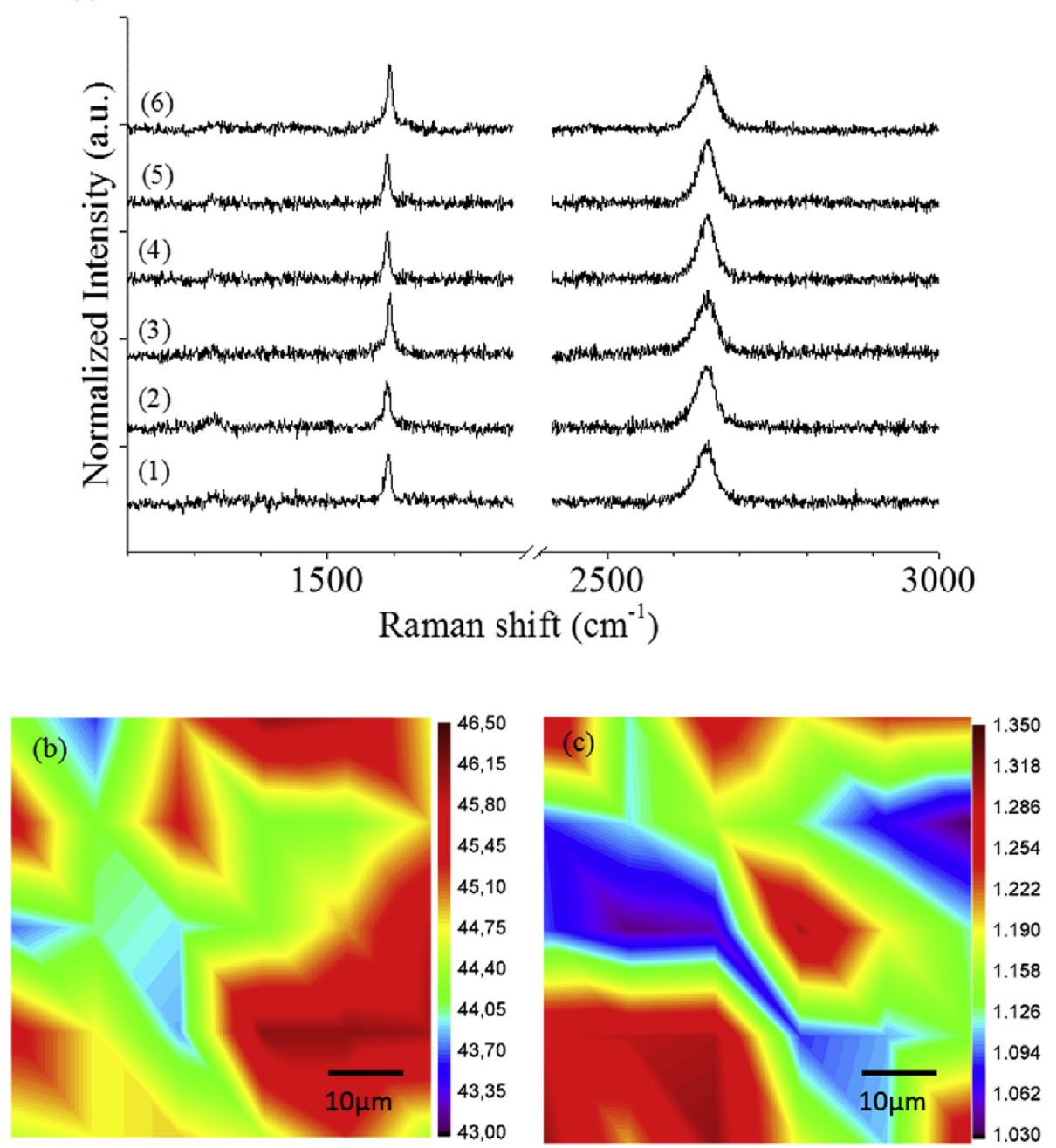

Fig. 3. (a) Raman spectra for six bilayer graphene samples after separation from Ni foil and transfer onto a silicon/silicon oxide wafer. Raman maps of (b) fwhm $\mathrm{m}_{2 \mathrm{D}}$ and (c) $\mathrm{I}_{2 \mathrm{D}} / \mathrm{I}_{\mathrm{G}}$ of the bilayer graphene grown under the sixth cycle. (A colour version of this figure can be viewed online.)

with a four-point collinear probe method (refer to supporting materials Fig. S3). The sheet resistance was around $774 \mathrm{Ohm} / \mathrm{sq}$ which is comparable with the values reported in previous report for stacked bilayer graphene [22]. One to notice, the graphene obtained after different cycles of reaction and separation, the crystallinity and the number of graphene layers are consistent.

The remaining Ni foil after underwent the separation process with both etchant are shown in Fig. S4. The surface of Ni foil after the separation using nitric acid is obviously different from the original $\mathrm{Ni}$ foil and that after the separation induced by iron nitrate solution. The surface of $\mathrm{Ni}$ foil became rough after in contact with nitric acid, especially at the edge of foil, due to the longer period exposed in acid and the formation of an oxidized layer. On the contrary, the surface of the $\mathrm{Ni}$ foil is seen like undamaged after being exposed to iron nitrate. Fig. 4 shows the AFM surface morphology of the Ni foil surface before and after the separation process. The surface of $\mathrm{Ni}$ foil after separation using iron nitrate was highly preserved, no severe damage are evidenced (Fig. 4(b)), except a few small holes of around $1 \mu \mathrm{m}$. For Ni foil exposed to nitric acid (Fig. 4(c)), the observed surface was highly uneven with a lot of protrusions. The surface flatness of $\mathrm{Ni}$ foil is important for success of graphene transfer. Under calculation with the software, XEI come along with AFM, the surface roughness were $46.20 \mathrm{~nm}, 176.27 \mathrm{~nm}$, $883.00 \mathrm{~nm}$ and $90.28 \mathrm{~nm}$ respectively for Fig. 4(a-d). If an untreated $\mathrm{Ni}$ foil from separation process is directly used for the growth of following graphene, the separated graphene is highly contaminated with un-removed $\mathrm{Ni}$ particles observable by optical microscopy (Fig. S5). To minimize the contaminating Ni particles on the separated graphene and reduce the roughness of $\mathrm{Ni}$ foil, the surface of the Ni foil was polished with sand paper prior to graphene growth (Fig. 4(d)). The surface roughness was highly reduced after polishing (from $883.00 \mathrm{~nm}$ to $90.28 \mathrm{~nm}$ ), so that more uniform and cleaner bilayer graphene could be obtained after subsequent CVD.

XRD pattern of the surface of nickel foil after graphene growth, and subsequent separation using iron nitrate solution or nitric acid are shown in Fig. 5 (insert). As expected, the diffraction peaks with high intensity at $2 \theta=52.1^{\circ}, 60.9^{\circ}, 91.5^{\circ}$ and $114.0^{\circ}$ assigned to (111), (200), (220) and (311) reflection of the super-lattice of $\mathrm{Ni}$ (fcc). If the range of $40^{\circ}-52^{\circ}$ was magnified (Fig. 5), less pronounced intensity peaks at $c a .2 \theta=46.3^{\circ}$ and $49.1^{\circ}$ which can be assigned to (110) and (006) peaks of rhombohedral $\mathrm{Ni}_{3} \mathrm{C}$. They are well noticeable on the three shown patterns, especially for the substrate just after the CVD deposit and that after separation using the iron nitrate solution. A weaker diffraction peak is also visible for the sample after separation by nitric acid in agreement with the strong character of that etchant.

$\mathrm{Ni}_{3} \mathrm{C}$ was also evidenced by XPS. The recorded $\mathrm{C} 1$ s core level 


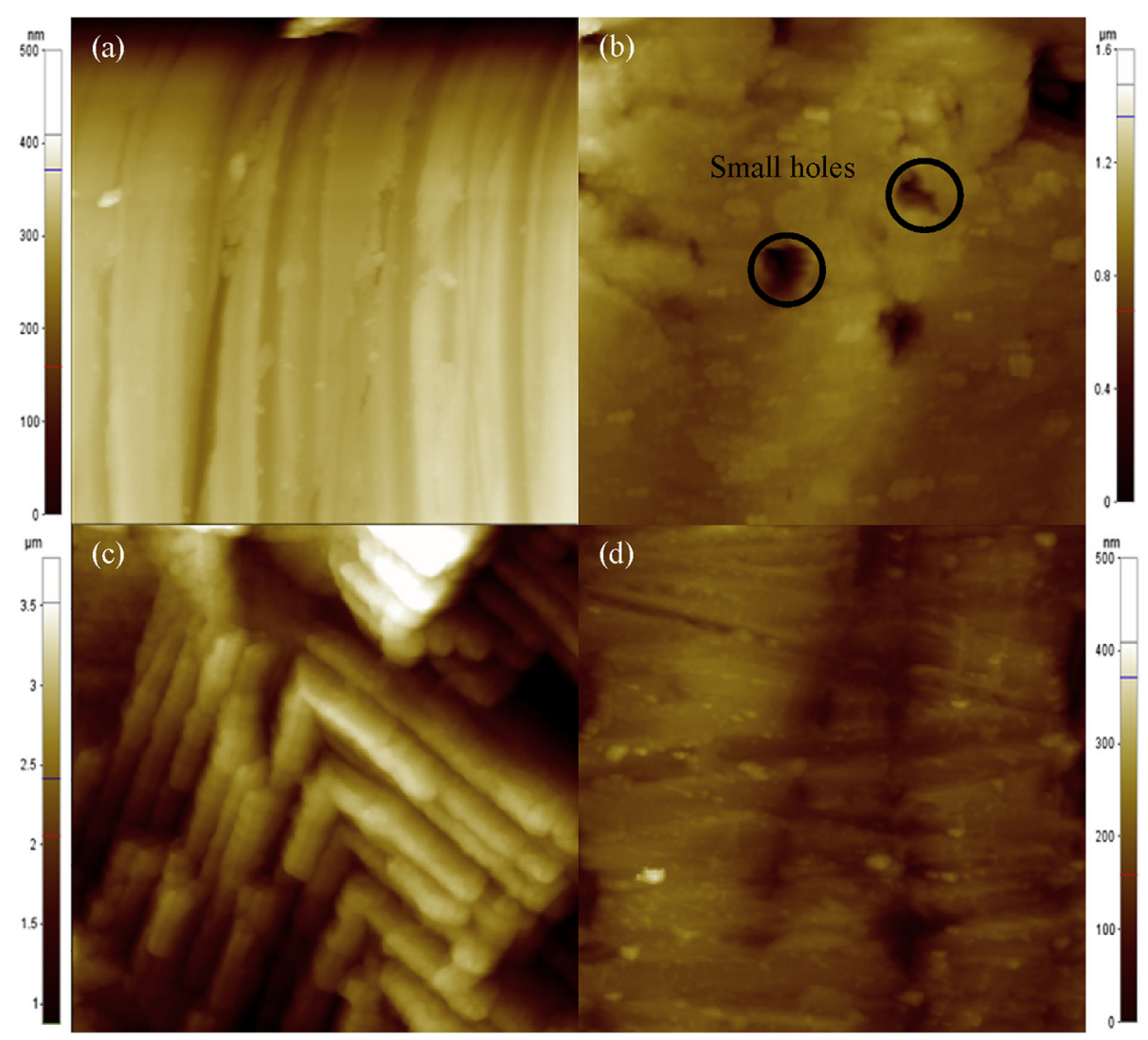

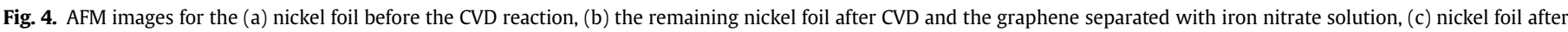

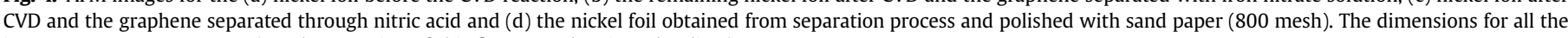
images are $15 \mu \mathrm{m} \times 15 \mu \mathrm{m}$. (A colour version of this figure can be viewed online.)

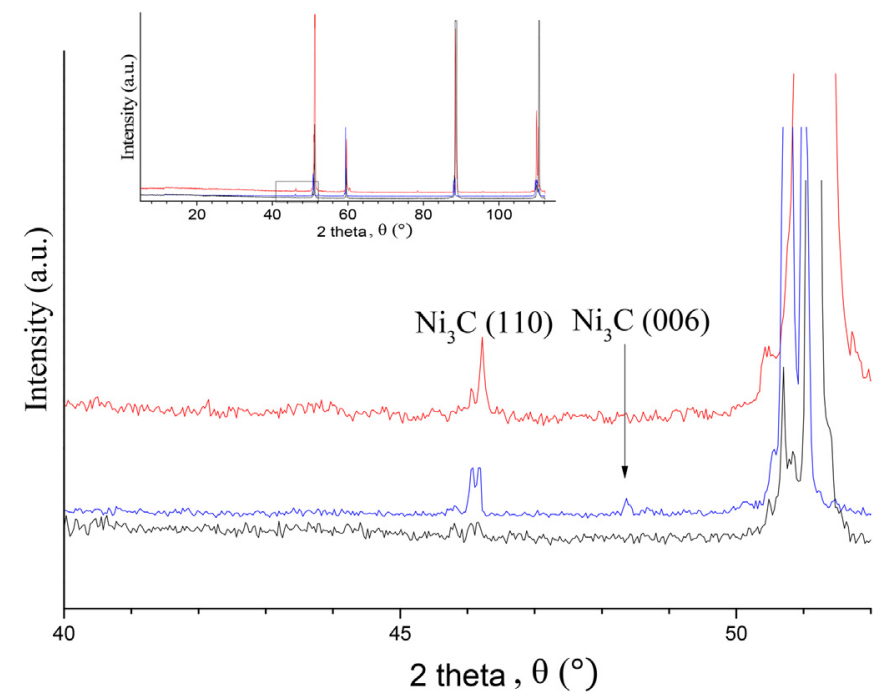

Fig. 5. XRD pattern of nickel foil after CVD (red), after the CVD and graphene separation using iron nitrate solution (blue) and after CVD and the graphene separation by nitric acid (black). (A colour version of this figure can be viewed online.)

displays two contributions, one at low binding energy around $283.8 \mathrm{eV}$ (arrow in Fig. 6) appearing as a shoulder of the main line at $284.4 \mathrm{eV}$ with a full width at half maximum (FWHM) of $0.8 \mathrm{eV}$, not far from the $0.65 \mathrm{eV}$ of experimental resolution. The main line is attributed to graphitic carbon, here probably from the grown bilayer graphene. The low energy line can be assigned to nickel carbide with a binding energy in good agreement with the literature [23-25].

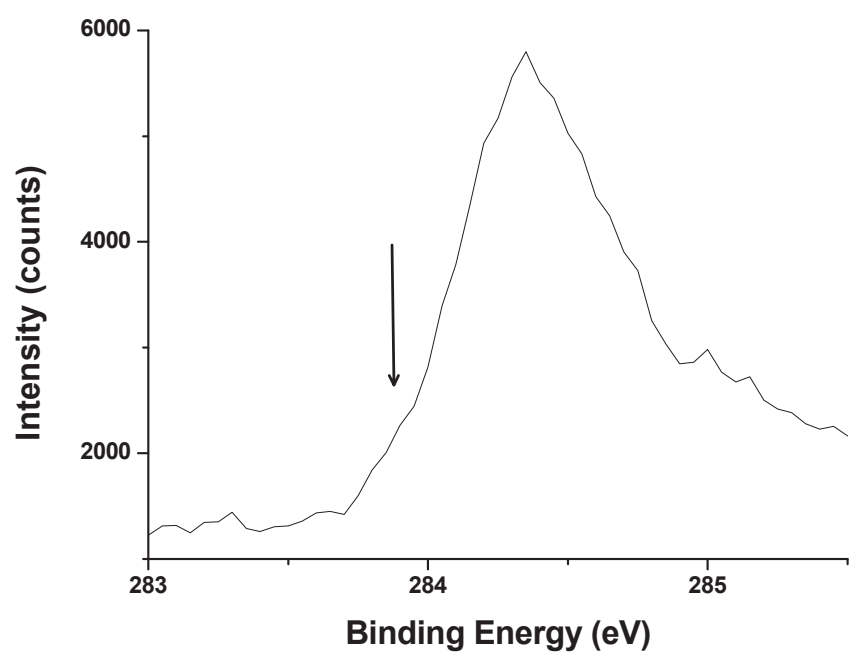

Fig. 6. C1s XPS spectra of the nickel foil after the CVD reaction; the arrow showing $\mathrm{Ni}_{3} \mathrm{C}$ contribution.

\section{Discussion}

\subsection{Graphene separation mechanism and cleanness of grown graphene}

We have shown that as the surface of the Ni foil is relatively smooth, intercalation and mild etching by iron nitrate solution would be easier to take place between graphene and Ni foil surface. 
The soft separation process is partly responsible for the graphene cleanliness (Fig. 7(a)). As nickel surface was exposed to nitric acid, the surface became highly uneven and full of protrusions resulted by the edge of grains of $\mathrm{Ni}$ (Fig. 4(c)). The conventional polycrystalline $\mathrm{Ni}$ foil is composed of numerous grains that are closely bounded. As reported by Zhang et al. [26], graphitic carbon could be accumulated in between the grains during the graphene growth stage. The presence of graphitic carbon probably weakens the interactions between the Ni grains and assists that way etchant to intercalate between the grains. This phenomenon is emphasized as nitric acid was utilized as etchant. The strong etching property of nitric acid attacks the surface of the Ni foil vigorously. Besides that, graphene usually mitigates the surface morphology of the catalyst. If an individual grain is over exposed, the interaction with neighboring grain is weakened leading to encapsulation of $\mathrm{Ni}$ grains by graphitic layers. Graphene is indeed known to strongly interact with Ni due to hybridization between $\pi$ orbitals of graphene and $\mathrm{d}_{\mathrm{z} 2}$ states $\mathrm{Ni}[27,28]$. The spacing between graphene and Ni surface is thus reduced and was calculated as low as $2.11 \AA$ [29]. It was reported that the $\pi$-band structure of graphene could not be found in the first two layers [30]. In that case, interaction between protruded grains and the foil is expected to be highly reduced. The graphitic layer prevents the encapsulated particles from being etched and results in high $\mathrm{Ni}$ residue on the transferred graphene (Fig. 7(b)). Encapsulated Ni particles were widely observed under HRTEM for graphene grown from $\mathrm{Ni}$ foil with rough surface (Fig. S6). We have shown that $\mathrm{Ni}$ residue on graphene could be minimized by a simple polishing process applied to the Ni foil using sand paper. The cleanliness of the transferred graphene could be preserved as $\mathrm{Ni}$ was smoothed under mild polishing conditions. It enabled the graphene separation to occur as illustrated in Fig. 7(a) and preserved the uniformity of bilayer graphene under various cycles.

\subsection{Protecting effect of nickel substrate by nickel carbide}

As already mentioned, acid and aqueous iron solution are widely used for the separation of graphene from both $\mathrm{Ni}$ or $\mathrm{Cu}$ substrate and normally, the substrates are etched away completely [31-33]. Indeed, if pure metal foil is placed into the etchant solution, it is rapidly solubilized even with weak concentrations. Interestingly, in our study, the etching rate of $\mathrm{Ni}$ was significantly reduced which allowed the $\mathrm{Ni}$ foil to be reused several times. $\mathrm{Ni}_{3} \mathrm{C}$ is known to offer good protection against corrosion. $\mathrm{Ni}_{3} \mathrm{C}$ was already reported in several patents for its use as an insulating layer covering $\mathrm{Ni}$ in order to inhibit oxidation and other chemical reactions [34-36]. Hence, $\mathrm{Ni}_{3} \mathrm{C}$ probably plays a crucial role to enable the reuse of $\mathrm{Ni}$ foil. From the $\mathrm{Ni}-\mathrm{C}$ phase diagram, the concentration of the diluted carbon adatom in the bulk $\mathrm{Ni}$ is as low as 0.9 at\% at $900{ }^{\circ} \mathrm{C}$. Under our CVD conditions, the amount of formed $\mathrm{Ni}_{3} \mathrm{C}$ is thereby expected to be small. The presence of small amount of $\mathrm{Ni}_{3} \mathrm{C}$ was also reported to be formed during [37] and after [38] the CVD reaction. However, in most of the studies, $\mathrm{Ni}_{3} \mathrm{C}$ was unfortunately unnoticed. We believe that the evidenced $\mathrm{Ni}_{3} \mathrm{C}$ present at the surface of our Ni foil after CVD could act as a shield to protect Ni foil from being fully etched by iron nitrate solution. It allowed the minimum loss of $\mathrm{Ni}$ foil during the separation process and permitted the reused of $\mathrm{Ni}$ foil for later CVD. But from Fig. 4(b), some etch pits observed on the surface of $\mathrm{Ni}$ foil, with the depth of around $1 \mu \mathrm{m}$, show that the $\mathrm{Ni}_{3} \mathrm{C}$ layer is not uniform on the nickel surface. That could provide weak points for the etchant attack. Meanwhile if stronger etchant like nitric acid was used, this non-uniformed and thin $\mathrm{Ni}_{3} \mathrm{C}$ could not preserve the perfectness of surface of $\mathrm{Ni}$ foil anymore. The presence of $\mathrm{Ni}_{3} \mathrm{C}$ is vital to inhibit the excessive etching of the $\mathrm{Ni}$ foil by mild etchant. Several conditions are required for the formation of sufficient $\mathrm{Ni}_{3} \mathrm{C}$. It will be elaborated in subsequent section.

\subsection{Graphene layer control by fast temperature quenching and formation of $\mathrm{Ni}_{3} \mathrm{C}$}

It is widely accepted that graphene formation follows a bulkmediated growth mechanism [2,39], whereas the concentration of carbon solubilized in nickel is relatively high compared with other catalyst. During the CVD process, the methane gas is catalytically decomposed at the surface of $\mathrm{Ni}$ foil and the carbon adatoms dissolve into bulk Ni (Fig. 8(a)). The nucleation process of graphene starts as the carbon concentration has achieved or above a threshold, especially during the cooling process (Fig. 8(b)). Referring to $\mathrm{Ni}-\mathrm{C}$ phase diagram, the carbon solubility in bulk $\mathrm{Ni}$ decreases with descending temperature, the excess of carbon would segregate from $\mathrm{Ni}$ upon cooling. $\mathrm{Fe}, \mathrm{Co}$ and $\mathrm{Ni}$ are among transition metals that are known to easily form carbides after expose to elevated temperature with carbon source [40]. The presence of $\mathrm{Ni}_{3} \mathrm{C}$ is however rarely reported in the area of the $\mathrm{Ni}$ catalysed CVD for the graphene synthesis. Presence of $\mathrm{Ni}_{3} \mathrm{C}$ is commonly reported at the surface of core-shell $\mathrm{Ni}-\mathrm{Ni}_{3} \mathrm{C}$ nanoparticles in the carbon nanotube (CNT) samples [41-43]. The growth conditions of CNTs and graphene differ especially regarding the control of dissolved carbon adatom into the bulk metal catalyst. Large amount of dissolved carbon adatom is favorable to increase the yield of CNT formation. Meanwhile, for graphene synthesis, the dissolved carbon is commonly lowered either through vacuum CVD [44], utilizing low ratio of carbon precursor to dilution gas, with very thin nickel film as catalyst [45] or introduce inhibitor in the system [15]. Under these conditions, carbon atoms could segregate and precipitate at the surface of Ni with the optimum level and lead to formation of monolayer or bilayer graphene which has the higher research value. Conversely, in our CVD process, the ratio of carbon precursor to dilution gas is 0.25 , which is much higher as compared to those usually reported for the growth of monolayer or bilayer graphene, for example 0.02 [44] or 0.04 [26]. Under our high carbon precursor concentration, the number of graphene layers was minimized to 2 by the very fast cooling we used. In comparison to other reported works with fast rates in the range of 10-600 C min ${ }^{-1}[13,26,45,46]$, our average cooling rate is much higher $\left(>900 \mathrm{C} \mathrm{min}^{-1}\right.$ ). Fast cooling facilitates the quenching (a)

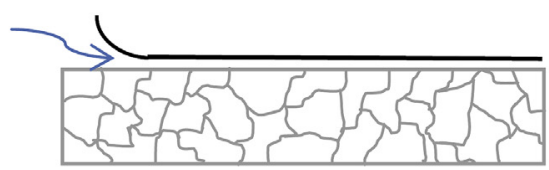

(b)

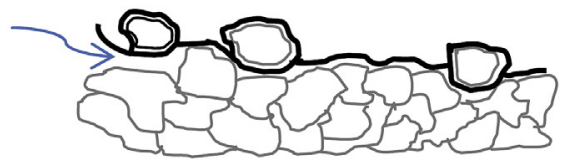

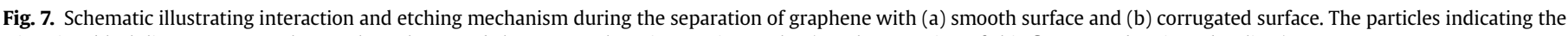
$\mathrm{Ni}$ grains, black line represents the graphene layer and the arrows show interacting paths. (A colour version of this figure can be viewed online.) 
(a)

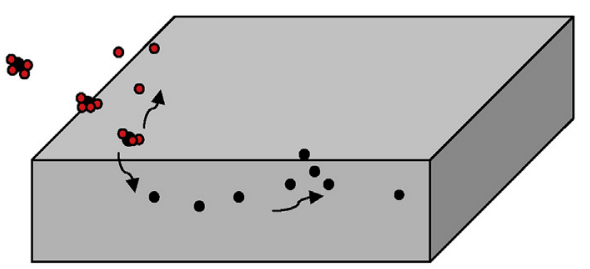

(b)

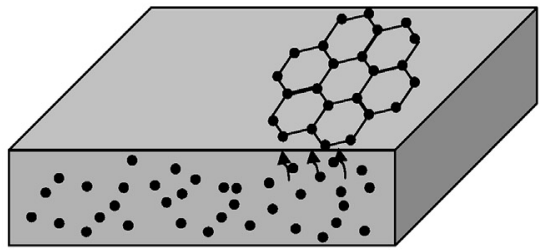

(c)

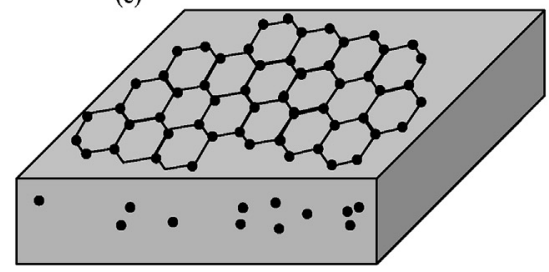

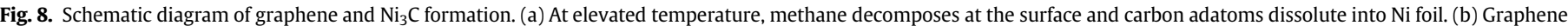

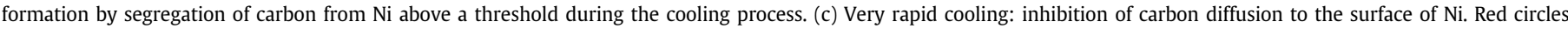
indicating hydrogen, meanwhile black circle represent carbon atoms. (A colour version of this figure can be viewed online.)

process and reduces the amount of carbon atoms segregated, only carbon situated near the surface had enough time to segregate and form graphene. Meanwhile, diffusion of carbon atoms in the middle of the Ni foil is highly inhibited. They would eventually formed $\mathrm{Ni}_{3} \mathrm{C}$, as evidenced by XRD and XPS (Figs. 5 and 6). Moreover, the thickness of the used $\mathrm{Ni}$ foil is quite elevated (125 $\mu \mathrm{m}$ instead of standard nanometer scale of thickness); leading to increase the amount of carbon atoms dissolved in nickel. At the same time, the longer diffusion path for the carbon adatoms certainly assists the trapping of carbon inside the $\mathrm{Ni}$ foil (Fig. 8(c)). This is the reason why presence of $\mathrm{Ni}_{3} \mathrm{C}$ is more obvious for iron nitrate treated $\mathrm{Ni}$ foil (blue) compared with the spectra before graphene separation (red) in Fig. 5. The etching of surface metallic Ni favors exposition of $\mathrm{Ni}_{3} \mathrm{C}$ to the surface. The fast cooling of $\mathrm{Ni}$ foil is the key step to create the necessary conditions for formation of $\mathrm{Ni}_{3} \mathrm{C}$ and control of the number of layers of the grown graphene. It subsequently facilitates the reuse of catalyst if the right etchant is used for graphene separation. If the catalyst was cooled naturally along with the furnace, which took around $6 \mathrm{~h}$, only multilayer graphene was obtained and the unable to carry out the reuse of catalyst. Most of the time, the Ni foils were fully etched away.

\section{Summary}

We have developed a very rapid cooling process for high-quality uniform bilayer graphene grown by Ni-catalyzed CVD growth. The proposed mechanism involves (i) bilayer graphene segregation quenching process, (ii) diffusion inhibition of the carbon dissolved inside the $\mathrm{Ni}$ foil and (iii) formation of $\mathrm{Ni}_{3} \mathrm{C}$ responsible for graphene cleanliness and catalyst reuse. The presence of $\mathrm{Ni}_{3} \mathrm{C}$ combined with the use of iron nitrate as soft etchant for the graphene separation enables the $\mathrm{Ni}$ foil to be reused again up to 6 cycles without causing huge deviation on the quality and uniformity of bilayer graphene. $\mathrm{Ni}_{3} \mathrm{C}$ is indeed able to limit the etching effect of the $\mathrm{Ni}$ foil. We have also shown that the surface smoothness of $\mathrm{Ni}$ foil before CVD is curial to ensure efficient separation of the grown graphene. A corrugated surface results in encapsulation of Ni grains on the graphene layer and makes the separation incomplete.

\section{Acknowledgment}

The authors gratefully acknowledge the financial support provided by Universiti Sains Malaysia (USM Fellowship), by Les Bourses du Gouvernement Français, the IRec grant (1002/PJKIMIA/ 910404), and the Fundamental Research Grant Scheme (FRGS) (203/PJKIMIA/6071278). The authors also thank Pascal Franchetti and Spiros Zafeiratos for their technical help and expertise during Raman and XPS measurements, respectively.

\section{Appendix A. Supplementary data}

Supplementary data related to this article can be found at http:// dx.doi.org/10.1016/j.carbon.2015.09.073.

\section{References}

[1] A. Bianco, H.-M. Cheng, T. Enoki, Y. Gogotsi, R.H. Hurt, N. Koratkar, et al., All in the graphene family: a recommended nomenclature for two-dimensiona carbon materials, Carbon 65 (0) (2013) 1-6.

[2] C.M. Seah, S.P. Chai, A. Mohamed, Mechanisms of graphene growth by chemical vapour deposition on transition metals, Carbon 70 (2014) 1-21.

[3] Y. Wang, Y. Zheng, X. Xu, E. Dubuisson, Q. Bao, J. Lu, et al., Electrochemical delamination of CVD-grown graphene film: toward the recyclable use of copper catalyst, ACS Nano 5 (12) (2011) 9927-9933.

[4] L. Gao, W. Ren, H. Xu, L. Jin, Z. Wang, T. Ma, et al., Repeated growth and bubbling transfer of graphene with millimetre-size single-crystal grains using platinum, Nat. Commun. 3 (2012) 699

[5] F. Pizzocchero, B.S. Jessen, P.R. Whelan, N. Kostesha, S. Lee, J.D. Buron, et al. Non-destructive electrochemical graphene transfer from reusable thin-film catalysts, Carbon 85 (0) (2015) 397-405.

[6] X. Li, W. Cai, L. Colombo, R.S. Ruoff, Evolution of graphene growth on ni and cu by carbon isotope labeling, Nano Lett. 9 (12) (2009) 4268-4272.

[7] ASM Hanbook, Alloy Phase Diagrams, ASM International, 2002.

[8] H. Shu, X. Chen, X. Tao, F. Ding, Edge structural stability and kinetics of graphene chemical vapor deposition growth, ACS Nano 6 (4) (2012) 3243-3250.

[9] S.M. Kozlov, F. Viñes, A. Görling, Bonding mechanisms of graphene on metal surfaces, J. Phys. Chem. C 116 (13) (2012) 7360-7366.

[10] J. Lahiri, T. Miller, L. Adamska, I.I. Oleynik, M. Batzill, Graphene growth on $\mathrm{Ni}(111)$ by transformation of a surface carbide, Nano Lett. 11 (2) (2011) $518-522$.

[11] J. Lahiri, T.S. Miller, A.J. Ross, L. Adamska, I.I. Oleynik, M. Batzill, Graphene growth and stability at nickel surfaces, New J. Phys. 13 (2011).

12] L.L. Patera, C. Africh, R.S. Weatherup, R. Blume, S. Bhardwaj, C. CastellarinCudia, et al., Situ observations of the atomistic mechanisms of Ni catalyzed low temperature graphene growth, ACS Nano 7 (9) (2013) 7901-7912.

[13] P. Jacobson, B. Stöger, A. Garhofer, G.S. Parkinson, M. Schmid, R. Caudillo, et al. Nickel carbide as a source of grain rotation in epitaxial graphene, ACS Nano 6 (4) (2012) 3564-3572.

[14] A. Grüneis, K. Kummer, D.V. Vyalikh, Dynamics of graphene growth on a meta surface: a time-dependent photoemission study, New J. Phys. 11 (2009).

[15] R.S. Weatherup, C. Baehtz, B. Dlubak, B.C. Bayer, P.R. Kidambi, R. Blume, et al. Introducing carbon diffusion barriers for uniform, high-quality graphene growth from solid sources, Nano Lett. 13 (10) (2013) 4624-4631. 
[16] C.M. Seah, S.P. Chai, S. Ichikawa, A. Mohamed, Synthesis of single-walled carbon nanotubes over a spin-coated Fe catalyst in an ethanol-PEG colloidal solution, Carbon 50 (3) (2012) 960-967.

[17] C.M. Seah, S.P. Chai, S. Ichikawa, A.R. Mohamed, Control of iron nanoparticle size by manipulating PEG-ethanol colloidal solutions and spin-coating parameters for the growth of single-walled carbon nanotubes, Particuology 11 (4) (2013) 394-400.

[18] A.C. Ferrari, J.C. Meyer, V. Scardaci, C. Casiraghi, M. Lazzeri, F. Mauri, et al., Raman spectrum of graphene and graphene layers, Phys. Rev. Lett. 97 (18) (2006) 187401.

[19] Z. Sun, Z. Yan, J. Yao, E. Beitler, Y. Zhu, J.M. Tour, Growth of graphene from solid carbon sources, Nature 468 (7323) (2010) 549-552.

[20] Z. Peng, Z. Yan, Z. Sun, J.M. Tour, Direct growth of bilayer graphene on SiO substrates by carbon diffusion through nickel, ACS Nano 5 (10) (2012) 8241-8247.

[21] Z. Yan, Z. Peng, Z. Sun, J. Yao, Y. Zhu, Z. Liu, et al., Growth of bilayer graphene on insulating substrates, ACS Nano 5 (10) (2011) 8187-8192.

[22] X. Li, C.W. Magnuson, A. Venugopal, R.M. Tromp, J.B. Hannon, E.M. Vogel, et al., Large-area graphene single crystals grown by low-pressure chemical vapo deposition of methane on copper, J. Am. Chem. Soc. 133 (9) (2011) $2816-2819$.

[23] A. Wiltner, C. Linsmeier, Thermally induced reaction and diffusion of carbon films on Ni(111) and Ni(100), Surf. Sci. 602 (23) (2008) 3623-3631.

[24] S. Rey, F. Le Normand, Surface transformations of carbon (graphene, graphite, diamond, carbide), deposited on polycrystalline nickel by hot filaments chemical vapour deposition, Thin Solid Films 519 (14) (2011) 4426-4428.

[25] A. Wiltner, C. Linsmeier, Formation of endothermic carbides on iron and nickel, Phys. Stat. Sol. A 201 (5) (2004) 881-887.

[26] Y. Zhang, L. Gomez, F.N. Ishikawa, A. Madaria, K. Ryu, C. Wang, et al., Comparison of graphene growth on single-crystalline and polycrystalline $\mathrm{Ni}$ by chemical vapor deposition, J. Phys. Chem. Lett. 1 (20) (2010) 3101-3107.

[27] F. Mittendorfer, A. Garhofer, J. Redinger, J. Klimeš, J. Harl, G. Kresse, Graphene on Ni(111): strong interaction and weak adsorption, Phys. Rev. B 84 (20) (2011) 201401.

[28] A. Dahal, M. Batzill, Graphene-nickel interfaces: a review, Nanoscale 6 (5) (2014) 2548-2562.

[29] Y. Gamo, A. Nagashima, M. Wakabayashi, M. Terai, C. Oshima, Atomic structure of monolayer graphite formed on Ni(111), Surf. Sci. 374 (1-3) (1997) $61-64$.

[30] J. Sun, J.B. Hannon, R.M. Tromp, P. Johari, A.A. Bol, V.B. Shenoy, et al., Spatiallyresolved structure and electronic properties of graphene on polycrystalline $\mathrm{Ni}$, ACS Nano 4 (12) (2010) 7073-7077.

[31] J.H. Seo, H.W. Lee, J.-K. Kim, D.-G. Kim, J.-W. Kang, M.-S. Kang, et al., Few layer graphene synthesized by filtered vacuum arc system using solid carbon source, Curr. Appl. Phys. 12 (2(0)) (2012) S131-S133.

[32] J.L. Oi, W.T. Zheng, X.H. Zheng, X. Wang, H.W. Tian, Relatively low temperature synthesis of graphene by radio frequency plasma enhanced chemical vapor deposition, Appl. Surf. Sci. 257 (15) (2011) 6531-6534.

[33] A. Reina, X. Jia, J. Ho, D. Nezich, H. Son, V. Bulovic, et al., Large area, few-layer graphene films on arbitrary substrates by chemical vapor deposition, Nano Lett. 9 (1) (2008) 30-35.

[34] Q. Zhang, B. Han, X. Tang, K. Heier, J.X. Li, J. Hoffman, et al., On the Mechanisms of carbon formation reaction on Ni(111) surface, J. Phys. Chem. C 116 (31) (2012) 16522-16531.

[35] W.C. Hasz, A.M. Thompson, M.P. Borom. Method of providing wear-resistant coatings, and related articles. U. S Patent 2002

[36] H. W. Armstrong. Decomposing carbide to elemental nickel. US Patents 1982

[37] R.S. Weatherup, B.C. Bayer, R. Blume, C. Ducati, C. Baehtz, R. Schlögl, et al., In situ characterization of alloy catalysts for low-temperature graphene growth, Nano Lett. 11 (10) (2011) 4154-4160.

[38] I.H. Son, H.J. Song, S. Kwon, A. Bachmatiuk, S.J. Lee, A. Benayad, et al., $\mathrm{CO}_{2}$ enhanced chemical vapor deposition growth of few-layer graphene over $\mathrm{NiO}_{\mathrm{x}}$, ACS Nano 8 (9) (2014) 9224-9232.

[39] M. Losurdo, M.M. Giangregorio, P. Capezzuto, G. Bruno, Graphene CVD growth on copper and nickel: role of hydrogen in kinetics and structure, Phys. Chem. Chem. Phys. 13 (46) (2011) 20836-20843.

[40] C.M. Seah, S.P. Chai, A.R. Mohamed, Synthesis of aligned carbon nanotubes, Carbon 49 (14) (2011) 4613-4635.

[41] M.K. Singh, P.P. Singh, E. Titus, D.S. Misra, F. LeNormand, High density of multiwalled carbon nanotubes observed on nickel electroplated copper substrates by microwave plasma chemical vapor deposition, Chem. Phys. Lett. $354(3-4)(2002) 331-336$.

[42] M.K. Singh, E. Titus, P.K. Tyagi, U. Palnitkar, D.S. Misra, M. Roy, et al., Ni and Ni/ Pt Filling inside multiwalled carbon nanotubes, J. Nanosci. Nanotechnol. 3 (1-1) (2003) 165-170

[43] N.T. Panagiotopoulos, E.K. Diamanti, L.E. Koutsokeras, M. Baikousi, E. Kordatos, T.E. Matikas, et al., Nanocomposite catalysts producing durable, super-black carbon nanotube systems: applications in solar thermal harvesting, ACS Nano 6 (12) (2012) 10475-10485.

[44] Y.Y. Tan, K.D.G.I. Jayawardena, A.A.D.T. Adikaari, L.W. Tan, J.V. Anguita, S.J. Henley, et al., Photo-thermal chemical vapor deposition growth of graphene, Carbon 50 (2) (2012) 668-673.

[45] M. Xu, D. Fujita, K. Sagisaka, E. Watanabe, N. Hanagata, Production of extended single-layer graphene, ACS Nano 5 (2) (2011) 1522-1528.

[46] K.S. Kim, Y. Zhao, H. Jang, S.Y. Lee, J.M. Kim, K.S. Kim, et al., Large-scale pattern growth of graphene films for stretchable transparent electrodes, Nature 457 (7230) (2009) 706-710. 